\title{
First experiences with the Spectrum Compact CE System
}

\author{
Nastasja Burgardt ${ }^{1}(\mathbb{C})$ Melanie Weissenberger ${ }^{1}(\mathbb{C}$
}

Received: 29 March 2021 / Accepted: 21 July 2021 / Published online: 19 October 2021

(c) The Author(s) 2021

\begin{abstract}
The newly released Spectrum Compact CE System by Promega is a capillary electrophoresis instrument developed for DNAfragment separation and sequencing. In this study, its compatibility to 8 commercial short tandem repeat (STR) kits from 4 different manufacturers, reproducibility (sizing precision, accuracy and concordance) and robustness (sensitivity and mixture resolution) were tested and compared to the ABI PRISM ${ }^{\circledR} 310$ Genetic Analyzer. The instrument was able to successfully analyse amplicons of all tested kits, proved to be as precise as claimed by manufacturer specifications and was shown to be more robust than the ABI PRISM® 310 Genetic Analyzer in some aspects. Analyses on the Spectrum Compact CE System were able to resolve peaks with length differences of 1-basepair in the short and long fragment range and mixtures of mixture ratios down to 1:30. We describe the advantages and limitations we have observed so far working with this instrument in our forensic genetics laboratory.
\end{abstract}

Keywords Spectrum Compact CE System $\cdot$ STR $\cdot$ Promega $\cdot$ DNA $\cdot$ Forensic genetics

\section{Introduction}

One of the most important steps of molecular genetic analysis is the separation and detection of DNA-fragments. Be it STR-analysis [1], sequencing [1], methylation analysis [2] or RNA-analysis [3], most molecular biology laboratories rely on some form of fragment separation to detect their analyte.

An effective way to achieve this separation is electrophoresis in combination with a sieving medium. In the beginning of DNA-profiling, slab-gel electrophoresis was used for that purpose [4]. But with the development of capillary electrophoresis (CE) separation methods in the early 1980s, research turned to applying CE to DNA analysis, since it requires less sample and solvent input and less run time, as well as offering a higher sample throughput and analysis sensitivity [5].

Nastasja Burgardt

nastasja.burgardt@med.uni-heidelberg.de

Melanie Weissenberger

melanie.weissenberger@med.uni-heidelberg.de

1 Institute of Forensic and Traffic Medicine, Department of Forensic Genetics, University Hospital Heidelberg, Voßstraße 2, Building 4420, 69115 Heidelberg, Germany
By 1988, commercial CE instruments started to be developed for a variety of applications [5]. The Dionex CESIA CE system (Dionex, Sunnyvale, CA, USA), the Applied Biosystems 270A-HT CE system (Applied Biosystems, Foster City, CA, USA) [6], the Beckman P/ACETM 2050 CE instrument (Beckman Instruments, Fullerton, CA, USA) [7, 8] and the Crystal CE System Model 310 (Unicam Corporation, Madison, WI, USA) [9], to name a few, were all tested and found to be suitable for application in Forensic DNA analysis. In 1996, Kuffner et al. [10] anticipated that evidence that has been analysed by capillary electrophoresis would soon be part of the judicial process and should be admissible (in US courts) since the method was, at that point, already widely accepted by the scientific community.

By the end of the 1990s, a CE system entered the market that was specialized for genotyping: the ABI PRISM ${ }^{\circledR}$ 310 Genetic Analyzer (Perkin Elmer, Applied Biosystems Division, Foster City, CA, USA) [11]. This single capillary instrument introduced the development and production of highly automated CE instruments for DNA analysis and is used in forensic genetics laboratories to this day.

In the 86 publications that can be found under the search terms "forensic genetics DNA" on https://pubmed.ncbi. nlm.nih.gov/ [12] released during the last year (accessed on 18.01.2021) that made use of electrophoresis, the results published were achieved with the fragment separation 
methods shown in Fig. 1. The publications stem from 28 different journals and cover a range of topics including population genetics, application and validation of new techniques and multiplexes, animal and plant genetics, methylation, kinship testing, RNA analysis and identification cases.

While these results suggest a high number of instrument diversity, most of the laboratories used one of the two Applied Biosystems ${ }^{\mathrm{TM}}$ Genetic Analyzers 3130 or 3500 (both by Life Technologies Corporation, Carlsbad, CA, USA) with different capillary array numbers.

A monopoly on $\mathrm{CE}$ instruments for genetic purposes on the one hand means that comparability between laboratories is facilitated and that expertise and experience can be accrued and put into new products. But on the other hand, it can also create a dependency on a singular manufacturer and hinder diversity and innovation.

After two decades since the development of DNA analysis CE instrumentation, each laboratory that is looking to invest in a new $\mathrm{CE}$ instrument first has to establish its requirements for a new instrument.

The decision for an acquisition should be based on a variety of factors: sample throughput, usage frequency, budget (purchase as well as long-term cost), laboratory space, number and kind of different users and kits that are supposed to run on the instrument, etc.

It would therefore be of importance that the market for $\mathrm{CE}$ instruments for DNA analysis reflects the diversity of laboratory needs.
This publication is based on the acquisition of a CE instrument as a replacement of/supplement to the 1-capillary ABI PRISM ${ }^{\circledR} 310$ Genetic Analyzer.

The replacement instrument requirements were as follows:

- comparable sample throughput to the ABI PRISM ${ }^{\circledR} 310$ Genetic Analyzer

- preferably new/with a recent release as to avoid a discontinuation of manufacturer support in the near future

- compatibility with the pre-established analysis software (GenoProof Mixture 2 by qualitype GmbH, Dresden, Germany)

- compatibility to kits of different suppliers (including 6-dye kits)

- economical solutions for consumables (no hard-stops, easy changing, etc.)

- equal or better analysis quality compared to the ABI PRISM® 310 Genetic Analyzer

- easily understandable user interface for fast training of new laboratory personnel

Since there are currently no other 1-capillary CE instruments available, the choice fell on a 4-capillary instrument, excluding instruments with higher sample throughput like the Applied Biosystems ${ }^{\mathrm{TM}}$ Genetic Analyzer 3500 since our laboratory requires smaller injection sizes.
Fig. 1 Pie chart of percentages of electrophoresis methods/ instruments used in forensic genetics publications released going back 1 year from 18.01.2021 $(n=86)$ on https:// pubmed.ncbi.nlm.nih.gov/, accessed under the search terms "forensic genetics DNA", G.A., Genetic Analyzer

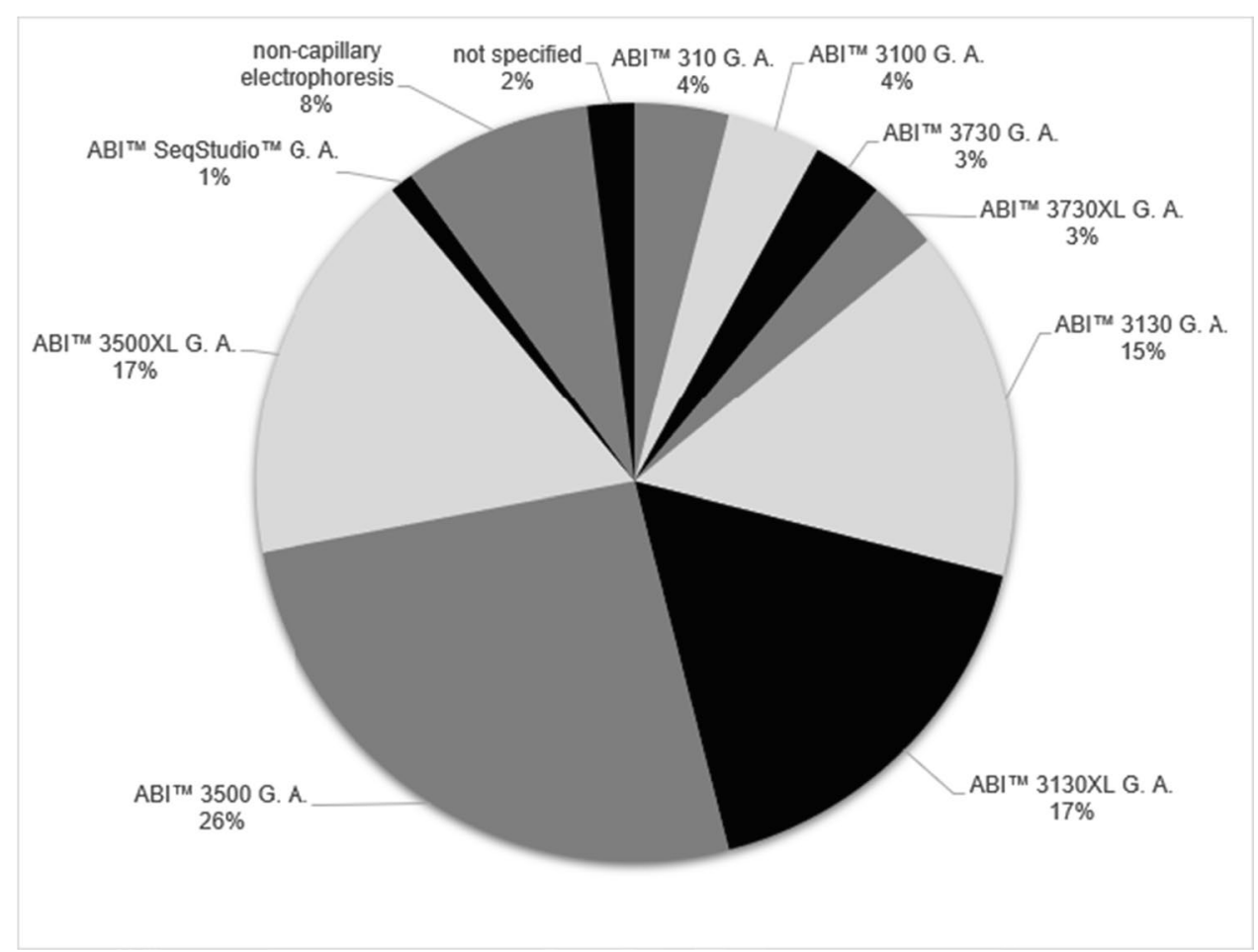


The Spectrum Compact CE System was newly released in 2020 as the first CE instrument by Promega developed in collaboration with Hitachi High-Tech [13].

Among the beforementioned requirements, the goal of this publication was to share the first experiences with the Spectrum Compact CE System in a forensic genetics laboratory and compare it to the ABI PRISM ${ }^{\circledR} 310$ Genetic Analyzer.

\section{Materials and methods}

\section{Instruments and consumables}

The instrument features and information about consumables for the ABI PRISM ${ }^{\circledR} 310$ Genetic Analyzer and the Spectrum Compact CE System are shown in Table 1.

The capillary of the ABI PRISM $® 310$ Genetic Analyzer was within its recommended number of injections, but other capillaries have regularly been used beyond expiry (up to 2000 injections). The capillary-array in the Spectrum Compact CE System used in this publication has been in use for over 5 months with a break of 3 weeks in between when it was removed from the instrument and was used up to 200 injections $(100 \%)$ beyond the recommended injection number.

The quality indicators given by the Spectrum Compact CE System were checked for each spectral calibration (quality value $\mathrm{QV}$ and condition number $\mathrm{CN}$ ) and each fragment analysis (sizing quality SQ and electrophoresis quality EQ).

All runs were performed at an environmental temperature of $25{ }^{\circ} \mathrm{C}$ (air condition controlled).

\section{Spectral calibration and compatibility}

\section{ABI PRISM ${ }^{\circledast} 310$ Genetic Analyzer}

For the analysis with the three STR-kits PowerPlex ${ }^{\circledR}$ ESX17, PowerPlex ${ }^{\circledR}$ Y23 (Promega, Fitchburg, WI, USA) and Investigator ${ }^{\circledR}$ Argus X-12 QS (Qiagen, Hilden, Germany), the colour filters G5v2 (for PowerPlex ${ }^{\circledR}$ ESX17 and PowerPlex ${ }^{\circledR}$ Y 23 ) and G5 (for Investigator ${ }^{\circledR}$ Argus X-12 QS) were used for the spectral calibration, as recommended by the manufacturers.

Each colour has been run separately and combined to a matrix according to the instruction of the manufacturers.

\section{Spectrum Compact CE System}

The spectral calibration was performed using the preinstalled assays (Table 2) on the Spectrum Compact CE System for the Spectrum Compact Polymer4. For each matrix, a dye set containing all colours of the STR kit was run on the four capillaries.

Eight STR-genotyping kits (PowerPlex ${ }^{\circledR}$ ESX17, PowerPlex ${ }^{\circledR}$ Y23, Investigator ${ }^{\circledR}$ Argus X-12 QS, Investigator ${ }^{\circledR} 24 p l e x$ QS (Qiagen, Hilden, Germany), Investigator ${ }^{\circledR}$ ESSplex SE QS (Qiagen, Hilden, Germany), Investigator ${ }^{\circledR}$ IDPlex Plus (Qiagen, Hilden, Germany), MPX5ESSv5 (Serac, Bad Homburg, Germany) and NGM Detect ${ }^{\mathrm{TM}}$ (Applied Biosystems ${ }^{\mathrm{TM}}$, Foster City, CA, USA) by four different suppliers were tested (matrix installation followed by a few sample test-runs, run conditions are shown in Table 3) to assess the flexibility of the instrument.

\section{Precision, accuracy and concordance}

To determine the precision of the Spectrum Compact CE System, two injections $(n=8)$ of the PowerPlex ${ }^{\circledR}$ ESX17 allelic ladder were analysed and compared between and within the injections by standard deviation (SD).

To determine the accuracy of the Spectrum Compact CE System, $n=27$ sample-runs (13 1-person-samples and 14 mixtures in 8 injections) were compared to one PowerPlex ${ }^{\circledR}$ ESX17 allelic ladder (injected as first on capillary 1) by mean base-pair (bp) deviation.

A total number of 109 samples with known results (known control alleles or comparison to ABI PRISM® 310 Genetic Analyzer results) were analysed with 6 different autosomal and 2 gonosomal kits to check for concordance.

\section{Baselines and carry-over}

To determine the noise-level of analyses of the Spectrum Compact CE System for the kits PowerPlex ${ }^{\circledR}$ ESX17, PowerPlex ${ }^{\circledR}$ Y23, Investigator ${ }^{\circledR}$ Argus X-12 QS and NGM Detect $^{\mathrm{TM}}$, the mean peak height of $n=10$ amplification negative controls per kit (analysed with the analytical threshold of $1 \mathrm{rfu}$ ) was calculated.

Based on these values, the limits of detection (LOD) and limits of quantitation (LOQ) were calculated separately for each colour channel by adding either 3 or 10 SD to the mean.

The same was done for PowerPlex ${ }^{\circledR}$ ESX17, PowerPlex ${ }^{\circledR}$ Y23 and Investigator ${ }^{\circledR}$ Argus X-12 QS amplicons on the ABI PRISM@ 310 Genetic Analyzer for comparison.

A high amount of DNA ( 4.73 ng DNA PCR-input) was analysed on the Spectrum Compact CE System to test for carry-over to the next injection (negative control).

\section{Dynamic range with thresholds}

To determine the dynamic range and analysis thresholds of the Spectrum Compact CE System, a dilution series of the positive amplification control $2800 \mathrm{M}$ (Promega) was 


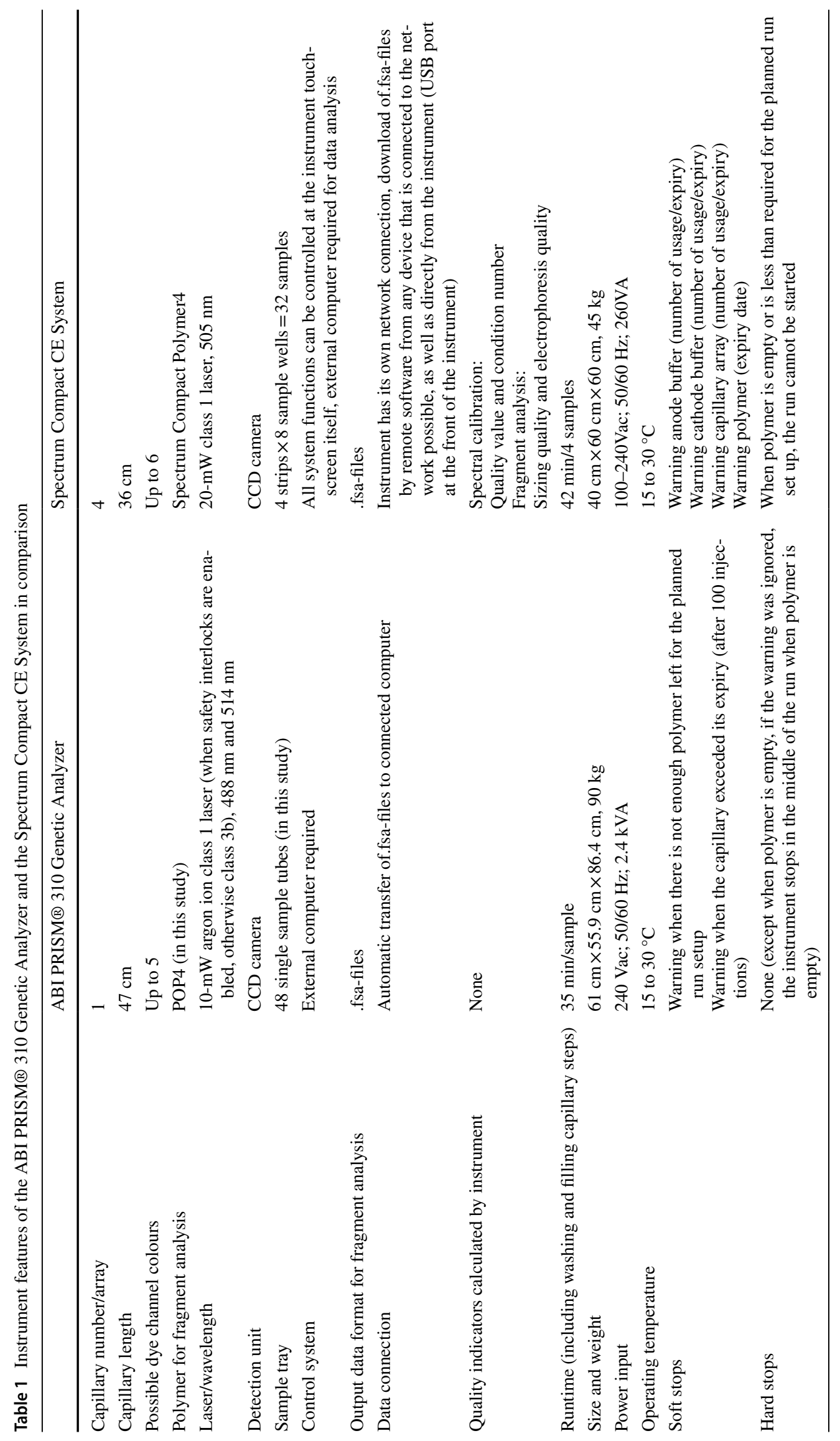


Table 2 STR-kits with corresponding pre-installed filter assay colour sets/run-assays that were used on the Spectrum Compact CE System

\begin{tabular}{|c|c|c|c|}
\hline Kit & Assay & Kit dyes & Filter assay colours \\
\hline MPX5ESSv5 & $\begin{array}{l}\text { Filter6_5Dye_O600(60-600)_36_ } \\
\text { P4 }\end{array}$ & $\begin{array}{l}\text { FAM, JOE-C6, YEL, RED \& } \\
\text { ORN }\end{array}$ & $\begin{array}{l}\text { 6-FAM }{ }^{\mathrm{TM}}, \mathrm{VIC} \circledast{ }^{\mathrm{N}} \mathrm{NED}^{\mathrm{TM}}, \mathrm{PET}^{\mathrm{TM}} \\
\text { \& LIZ }\end{array}$ \\
\hline NGM Detect ${ }^{\mathrm{TM}}$ & T_6Dye_O600(60-600)_36_P4 & $\begin{array}{l}\text { 6-FAM } \\
\text { TAM }, \text { VIC } \\
\text { TAM }{ }^{\mathrm{TM}}, \text { SED }^{\mathrm{TM}} \text {, } \\
\text { SIM } \& \text { LIZ }^{\mathrm{TM}}\end{array}$ & $\begin{array}{l}\text { 6-FAM }{ }^{\mathrm{TM}}, \mathrm{VIC}^{\mathrm{TM}}, \mathrm{NED}^{\mathrm{TM}}, \mathrm{TAZ}^{\mathrm{TM}}, \\
\text { SID }^{\mathrm{TM}}, \mathrm{LIZ}^{\mathrm{TM}}\end{array}$ \\
\hline $\begin{array}{l}\text { PowerPlex® ESX17 \& Power- } \\
\text { Plex® Y23 }\end{array}$ & Promega_5Dye_WENILS_36_P4 & $\begin{array}{l}\text { Fluorescein, JOE, TMR-ET, } \\
\text { CXR-ET \& WEN }\end{array}$ & $\begin{array}{l}\text { Fluorescein, JOE, TMR-ET, CXR- } \\
\text { ET \& WEN }\end{array}$ \\
\hline $\begin{array}{l}\text { Investigator }{ }^{\circledR} \text { Argus X-12 QS, } \\
\text { Investigator }{ }^{\circledR} \text { ESSplex SE QS \& } \\
\text { Investigator }{ }^{\circledR} \text { IDPlex Plus }\end{array}$ & Q_5Dye_BTO550_36_P4 & $\begin{array}{l}\text { 6-FAM }{ }^{\mathrm{TM}}, \mathrm{BTG}, \mathrm{BTY}, \mathrm{BTR} \& \\
\text { BTO }\end{array}$ & $\begin{array}{l}\text { 6-FAM }{ }^{\mathrm{TM}}, \mathrm{BTG}, \mathrm{BTY}, \mathrm{BTR} \& \\
\text { BTO }\end{array}$ \\
\hline Investigator ${ }^{\circledR} 24$ plex QS & Q_6Dye_BTO550_36_P4 & $\begin{array}{l}\text { 6-FAM }{ }^{\mathrm{TM}}, \mathrm{BTG}, \mathrm{BTY}, \mathrm{BTR} 2, \\
\text { BTP \& BTO }\end{array}$ & $\begin{array}{l}\text { 6-FAM }{ }^{\mathrm{TM}}, \mathrm{BTG}, \mathrm{BTY}, \mathrm{BTR} 2, \mathrm{BTP} \\
\text { \& BTO }\end{array}$ \\
\hline
\end{tabular}

Table 3 Run conditions used on the ABI PRISM® 310 Genetic Analyzer and Spectrum Compact CE System

\begin{tabular}{llllll}
\hline Instrument & Injection time & Injection voltage & Run voltage & Run temperature & Run time \\
\hline ABI PRISM® & $5 \mathrm{~s}$ & $15 \mathrm{kV}$ & $15 \mathrm{kV}$ & $60{ }^{\circ} \mathrm{C}$ & $28 \mathrm{~min}$ \\
$\begin{array}{l}310 \text { Genetic } \\
\text { Analyzer }\end{array}$ & & & & \\
$\begin{array}{l}\text { Spectrum } \\
\text { Compact CE }\end{array}$ & $9 \mathrm{~s}$ & $1.6 \mathrm{kV}$ & $13 \mathrm{kV}$ & $60{ }^{\circ} \mathrm{C}$ & $32.17 \mathrm{~min}$ \\
System & & & & \\
\hline
\end{tabular}

amplified in duplicate with the PowerPlex ${ }^{\circledR}$ ESX17 kit and each sample was then analysed in quadruplicate $(n=76)$.

The 750 pg-level was not amplified in duplicate as it was added at the second amplification.

The 10 calculated dilution levels were as follows:

2ng, $1 \mathrm{ng}, 750 \mathrm{pg}, 500 \mathrm{pg}, 250 \mathrm{pg}, 125 \mathrm{pg}, 62.5 \mathrm{pg}$, $31.25 \mathrm{pg}, 15.63 \mathrm{pg}$ and $7.81 \mathrm{pg}$

The dilution series was set up based on the concentration given on the amplification control (10 ng/ $\mu \mathrm{L}) .2800 \mathrm{M}$ concentration is measured by the manufacturer by PowerQuant ${ }^{\circledR}$ Real-Time Assay analysis with the specifications of an acceptable range of 9-11 ng/uL and an A260/280 ratio of $>1.75$ [14].

Concentrations were confirmed by measurements with the QuantiFluor® dsDNA system on a Quantus fluorometer (both by Promega) down to $62.5 \mathrm{pg}$. Below that dilution, measurement data became unreliable and DNA amounts are given in approximate calculated values.

The limits of linearity (LOL) were determined separately for each colour channel.

The stochastic threshold was defined by the mean of all heterozygous peaks at DNA template input levels where drop-outs occur plus 3 SD [15].

The limit of linearity was defined as the highest measured on-scale (without flat-tops or splits) allele peak in a heterozygous locus.
The LOL was then combined with the LOD and the LOQ to create an overview over the range, in which a linear relationship between signal and DNA-input amount can be expected (dynamic range of the Spectrum Compact $\mathrm{CE}$ System).

A replicate of all amplicons was analysed on the ABI PRISM® 310 Genetic Analyzer for comparison.

Allele calls were made based on the LODs determined in section "Baselines and carry-over".

\section{1-bp resolution}

To assess the 1-bp resolution of the Spectrum Compact CE System, the peak-to-valley ratio (valley height divided by the smaller peak height) of alleles that differ in 1-bp in D1S1656 was calculated with $n=29$ (2 amplicons of the Gednap 47 trace 4 sample amplified with PowerPlex ${ }^{\circledR}$ ESX17 and 5 PowerPlex ${ }^{\circledR}$ ESX17 allelic ladders) for the shorter fragment region (155-170 bp) and $n=24$ (2 amplicons of the Gednap 47 trace 4 sample amplified with NGM Detect ${ }^{\mathrm{TM}}$ and $5 \mathrm{NGM}^{\text {Detect }}{ }^{\mathrm{TM}}$ allelic ladders) for the longer fragment region (290-360 bp).

This was compared to the peak-to-valley ratios of 1 amplicon of the Gednap 47 trace 4 sample amplified with PowerPlex ${ }^{\circledR}$ ESX17 and 5 PowerPlex ${ }^{\circledR}$ ESX17 allelic ladders $(n=27)$ run on the ABI PRISM® 310 Genetic Analyzer. 


\section{Mixture resolution}

A mixture of the positive amplification controls $2800 \mathrm{M}$ (PowerPlex ${ }^{\circledR}$ ESX17 kit control) and DNA Control 007 (NGM Detect ${ }^{\mathrm{TM}}$ kit control) in five mixture ratios $(1: 1,1: 5$, $1: 10,1: 20,1: 30)$ was amplified in duplicate with the PowerPlex® ESX17 kit and analysed in duplicate on the Spectrum Compact CE System.

The same amplicons were analysed on the ABI PRISM ${ }^{\circledR}$ 310 Genetic Analyzer for comparison.

The calculated DNA template amounts chosen for the mixture of $2800 \mathrm{M}$ (major contributor) and DNA Control 007 (minor contributor) were as follows:

$250 \mathrm{pg}+250 \mathrm{pg}$ for the $1: 1$ mixture

$500 \mathrm{pg}+100 \mathrm{pg}$ for the $5: 1$ mixture

$750 \mathrm{pg}+75 \mathrm{pg}$ for the $10: 1$ mixture

$1 \mathrm{ng}+50 \mathrm{pg}$ for the 20:1 mixture

and $1 \mathrm{ng}+33 \mathrm{pg}$ for the $30: 1$ mixture.

One nanogram was chosen as the maximum DNA template input as the Spectrum Compact CE System showed to reach its limit of linearity at that DNA template amount.

The mixtures were set up based on the concentration given on the amplification controls $(10 \mathrm{ng} / \mu \mathrm{L}$ on $2800 \mathrm{M}$ and $0.1 \mathrm{ng}$ on DNA Control 007). The concentrations of the positive controls were confirmed by measurements with the QuantiFluor ${ }^{\circledR}$ dsDNA system on a Quantus fluorometer.

\section{Colour channel balance, heterozygote ratios and stutter ratios}

The colour channel balances and stutter incidences/ratios for the kits PowerPlex ${ }^{\circledR}$ ESX17, PowerPlex ${ }^{\circledR}$ Y23, Investigator ${ }^{\circledR}$ Argus X-12 QS and NGM Detect ${ }^{\mathrm{TM}}$, as well as the heterozygote ratios for the kits PowerPlex ${ }^{\circledR}$ ESX17, Investigator ${ }^{\circledR}$ Argus X-12 QS and NGM Detect ${ }^{\mathrm{TM}}$ were calculated based on 1-person profiles with ideal DNA template input of $\sim 250 \mathrm{pg}$ ( $n=17$ per instrument per kit for the colour channel balances and heterozygote ratios and $n=10$ per instrument per kit for the stutter ratios). NGM Detect ${ }^{\mathrm{TM}}$ data was only generated on the Spectrum Compact CE System, since the ABI PRISM® 310 Genetic Analyzer cannot support 6 colour dye kits.

\section{Sample analysis}

\section{Samples, extractions and quantification}

The samples used for this study were Gednap proficiency test samples, DGAB (Deutsche Gesellschaft für Abstammungsbegutachtung) proficiency test samples, positive controls from commercial PCR-kits and known samples of individuals who have given their written consent to use their buccal swab DNA extracts for scientific purposes according to $\S 13$ of the German law of genetic diagnostics. The sample extractions were done using either a Chelex-extraction [16] or the GEN-IAL ${ }^{\circledR}$ First-DNA all tissue kit (GEN-IAL $\mathrm{GmbH}$, Troisdorf, Germany).

All DNA samples (except for the mixtures) and positive controls were quantified by measuring $2 \mu \mathrm{L}$ of each extract (with a second confirmation measurement that had to lie between $\pm 0.03 \mathrm{ng} / \mu \mathrm{L}$ of the original measurement) using the QuantiFluor ${ }^{\circledR}$ dsDNA system on a Quantus fluorometer. The samples were then (if needed) diluted for the PCR according to those measurements.

\section{PCR, CE and data analysis}

All PCR amplifications were carried out on a Biometra Trio 30 (Analytik Jena, Jena, Germany). For the autosomal Qiagen kits (Investigator ${ }^{\circledR}$ ESSplex SE QS, Investigator ${ }^{\circledR}$ IDPlex Plus and Investigator ${ }^{\circledR} 24$ plex QS), the full recommended reaction volume of $25 \mu \mathrm{L}$ per sample was used since these kits were not previously validated in our laboratory. All other kits were applied with a reduced reaction volume of $12.5 \mu \mathrm{L}$ per sample.

For injection on the Spectrum Compact CE System, $1 \mu \mathrm{L}$ of PCR product was combined with the internal size standard according to the manufacturer of the STR-kit and 9.5 $\mu \mathrm{L} \mathrm{Hi}^{-\mathrm{Di}^{\mathrm{TM}} \text {-formamide (Applied Biosystems }}{ }^{\mathrm{TM}}$ ) in MicroAmp $^{\mathrm{TM}}$ Optical 8-Tube Strips $(0.2 \mathrm{~mL}$ ) (Applied Biosystems $\left.^{\mathrm{TM}}\right)$. The strips were covered with "Strip Septa Mat, 8-Well" strip septa mats (Promega) and the contents were vortexed, spun down, denatured at $95{ }^{\circ} \mathrm{C}$ for $3 \mathrm{~min}$ and then snap-cooled on a cold block for a minimum of $2 \mathrm{~min}$. The sample strips were set up using Spectrum Compact Control Software and then loaded onto the Spectrum Compact CE System.

All PCR products were separated by capillary electrophoresis on the Spectrum Compact CE System using a 36-cm 4-capillary array filled with Spectrum Compact Polymer4 (Promega).

The comparison samples were analysed on the ABI PRISM ${ }^{\circledR} 310$ Genetic Analyzer according to manufacturer guidelines.

The analysis of the.fsa data was carried out with the GenoProof Mixture 2 software (qualitype GmbH, Dresden, Germany).

\section{Run conditions}

The run conditions on the ABI PRISM ${ }^{\circledR} 310$ Genetic Analyzer and the Spectrum Compact CE System are shown in Table 3. 


\section{Results}

\section{Instruments and consumables}

All run quality indicators (sizing quality and electrophoresis quality) on the Spectrum Compact CE System were always passed, except for the MPX5ESSv5 runs. Despite the failed quality indicators, interpretable and correct electropherograms were produced (example supplemental Fig. 6 in "Online Resource 1").

With 200 more injections than the recommended 200, the EQ values given by the Spectrum Compact CE System of the capillary used in this study are still satisfactory for analysis (meaning that the EQ values of the analyses are $\geq 400$ ).

\section{Spectral calibration and compatibility}

The quality values and condition numbers calculated by the Spectrum Compact CE System for its spectral calibrations for five different matrices (Promega 5-dye, T6dye, Q5dye, Q6dye and Filter6 5dye), as well as the minimum quality value and the maximum condition number that is used by the instrument to decide between fail and pass, are shown in Table 4.

Example electropherograms of amplifications with MPX5ESSv5, NGM Detect ${ }^{\mathrm{TM}}$, PowerPlex ${ }^{\circledR}$ ESX17,
PowerPlex® Y23, Investigator ${ }^{\circledR}$ Argus X-12 QS, Investigator ${ }^{\circledR}$ ESSplex SE QS, Investigator ${ }^{\circledR}$ IDPlex Plus and Investigator ${ }^{\circledR} 24 p l e x$ QS are shown in "Online Resource 1" (supplemental Figs. 6-13).

\section{Precision, accuracy and concordance}

The highest SD calculated for the Spectrum Compact CE System based on $n=8$ PowerPlex ${ }^{\circledR}$ ESX17 ladders was $0.07 \mathrm{bp}$. There was no significant difference in deviation between and within the injections.

In a run of 27 PowerPlex $®$ ESX17 amplicons (8 injections), the mean deviation of the samples from the allelic ladder (injection 1, capillary 1) was $0.10 \mathrm{bp}$. The highest deviation was 0.38 bp in the locus D18S51 (injection 7, capillary 3$)$.

A total of 109 samples were tested with the Spectrum Compact CE System with 6 different autosomal and 2 gonosomal kits and were all concordant with the expected results.

\section{Baselines and carry-over}

The calculated LODs and LOQs (rounded to the closest 5-value) for the Kits PowerPlex ${ }^{\circledR}$ ESX17, PowerPlex ${ }^{\circledR}$ Y23 and Investigator ${ }^{\circledR}$ Argus X-12 QS for both instruments and for the kit NGM Detect ${ }^{\mathrm{TM}}$ on the Spectrum Compact CE
Table 4 Spectral calibration parameter pass conditions and measured values for all four capillaries of the capillary-array of the Spectrum Compact CE System

\begin{tabular}{|c|c|c|c|c|c|}
\hline & Min. quality value & $\begin{array}{l}\text { Max. condi- } \\
\text { tion number }\end{array}$ & $\begin{array}{l}\text { Capillary } \\
\text { number }\end{array}$ & $\begin{array}{l}\text { Quality value } \\
\text { measured }\end{array}$ & $\begin{array}{l}\text { Condition } \\
\text { number meas- } \\
\text { ured }\end{array}$ \\
\hline \multirow[t]{4}{*}{ Promega 5-DYE } & \multirow[t]{4}{*}{$\geq 0.95$} & \multirow[t]{4}{*}{$\leq 8.5$} & 1 & 0.996 & 5.66 \\
\hline & & & 2 & 0.996 & 5.81 \\
\hline & & & 3 & 0.995 & 5.67 \\
\hline & & & 4 & 0.997 & 5.54 \\
\hline \multirow[t]{4}{*}{ T6dye } & \multirow[t]{4}{*}{$\geq 0.95$} & \multirow[t]{4}{*}{$\leq 8.0$} & 1 & 0.995 & 5.91 \\
\hline & & & 2 & 0.991 & 6.30 \\
\hline & & & 3 & 0.994 & 6.05 \\
\hline & & & 4 & 0.998 & 5.90 \\
\hline \multirow[t]{4}{*}{ Q5dye } & \multirow[t]{4}{*}{$\geq 0.95$} & \multirow[t]{4}{*}{$\leq 20$} & 1 & 0.994 & 6.84 \\
\hline & & & 2 & 0.994 & 6.78 \\
\hline & & & 3 & 0.996 & 6.75 \\
\hline & & & 4 & 0.994 & 6.73 \\
\hline \multirow[t]{4}{*}{ Q6dye } & \multirow[t]{4}{*}{$\geq 0.95$} & \multirow[t]{4}{*}{$\leq 13.5$} & 1 & 0.993 & 11.19 \\
\hline & & & 2 & 0.993 & 11.23 \\
\hline & & & 3 & 0.991 & 11.16 \\
\hline & & & 4 & 0.996 & 11.08 \\
\hline \multirow[t]{4}{*}{ Filter6 5dye } & \multirow[t]{4}{*}{$\geq 0.95$} & \multirow[t]{4}{*}{$\leq 13.5$} & 1 & 0.979 & 6.13 \\
\hline & & & 2 & 0.997 & 6.83 \\
\hline & & & 3 & 0.998 & 6.71 \\
\hline & & & 4 & 0.997 & 6.62 \\
\hline
\end{tabular}


System are shown in Table 5 and supplemental Table 1 in "Online Resource 1".

The negative control that was run on the Spectrum Compact CE System on the same capillary after an amplicon of $\sim 4.73$ ng DNA showed no carry-over.

\section{Dynamic range and thresholds}

\section{Dilution series}

At 2 ng DNA template input, off-scale peaks and pull-ups occurred on both instruments and in both amplicons.

At $1 \mathrm{ng}$ DNA template input on the Spectrum Compact CE System, off-scale peaks occurred mostly in one amplicon, while in the other, only the single homozygous system in the yellow channel (D22S1045 allele 16 at $~ 101.5 \mathrm{bp}$ ) and therefore its neighbouring allele 15 in system D10S 1248 (at $\sim 101.5 \mathrm{bp}$ ) in the green channel were partially off-scale because of the spectral overlap. At $1 \mathrm{ng}$ DNA template input on the ABI PRISM ${ }^{\circledR} 310$ Genetic Analyzer, off-scale peaks and strong pull-ups occurred in both amplicons.

At 750 pg DNA template input on the Spectrum Compact CE System, off-scale peaks only occurred in the single homozygous system (D22S1045) and allele 15 in D10S1248 (see to $1 \mathrm{ng}$ ). In the single $750 \mathrm{pg}$ analysis performed on the ABI PRISM $® 310$ Genetic Analyzer, off-scale peaks occurred in D22S1045 and D12S391 and strong pull-ups throughout all colour channels.

At 500 pg DNA template input on the Spectrum Compact CE System, only the single homozygous system (D22S1045) and allele 15 in D10S1248 (see to $1 \mathrm{ng}$ ) showed off-scale peaks, while off-scale peaks in D2S441 and D12S391 and small pull-ups were observed on the ABI PRISM ${ }^{\circledR} 310$ Genetic Analyzer.

At 250 pg DNA template input, both instruments produced full on-scale profiles without pull-ups.

At $125 \mathrm{pg}$ DNA template input, the heterozygote ratio fell below $60 \%$ in 6 of the systems on both instruments, with the lowest observed heterozygote ratio observed being at around $32 \%$ in D8S1179 on both instruments. Both instruments produced full on-scale profiles.
At $62.5 \mathrm{pg}$ DNA template input, full on-scale profiles with heterozygote ratios of down to around $30 \%$ are produced on both instruments.

At 31 pg DNA template input, full on-scale profiles with heterozygote ratios of down to $10 \%$ are produced on both instruments.

At $\sim 16$ pg DNA template input on the Spectrum Compact CE System, first full and partial drop-outs occurred (6\% of expected alleles missing) with the tallest false homozygote observed at $421 \mathrm{rfu}$ in the D16S539 system. On the ABI PRISM® 310 Genetic Analyzer, full and partial dropouts ( $9 \%$ of expected alleles missing) were observed, with the tallest false homozygote being $296 \mathrm{rfu}$ in the D16S539 system.

At $\sim 8$ pg DNA template input on the Spectrum Compact CE System, full and partial drop-outs (29\% of expected alleles missing) were observed. On the ABI PRISM® 310 Genetic Analyzer, full and partial drop-outs occurred (33\% of expected alleles missing).

\section{Stochastic threshold}

Based on the mean of all heterozygous peaks at DNA template input levels where drop-outs occur $(\sim 16 \mathrm{pg}$ and $\sim 8 \mathrm{pg})$ plus $3 \mathrm{SD}$, the stochastic thresholds for the PowerPlex ${ }^{\circledR}$ ESX17 kit were determined as $424 \mathrm{rfu}$ on the ABI PRISM ${ }^{\circledR}$ 310 Genetic Analyzer and 670 rfu on the Spectrum Compact CE System.

\section{Dynamic range and limit of linearity}

The highest on-scale peaks of the dilution series analysed on the Spectrum Compact CE System were observed at $1 \mathrm{ng}$ DNA template input at 32,560 rfu in the blue colour channel, $26,242 \mathrm{rfu}$ in the green colour channel, 31,699 rfu in the yellow colour channel and 29,898 rfu in the red colour channel. The LOL was therefore reached at $1 \mathrm{ng}$ DNA template input, since no linear signal/template relationship was observed after this point.

The highest on-scale peaks of the dilution series analysed on the ABI PRISM 310 Genetic Analyzer were observed at $7444 \mathrm{rfu}$ in the blue colour channel (at $750 \mathrm{pg}$ DNA template input), $7289 \mathrm{rfu}$ in the green colour channel (at $500 \mathrm{pg}$
Table 5 Limits of detection (LOD) and limits of quantitation (LOQ) on the Spectrum Compact CE System $(n=40)$ for the kits PowerPlex ${ }^{\circledR}$ ESX17, PowerPlex ${ }^{\circledR}$ Y23, Investigator® Argus X-12 QS and NGM Detect ${ }^{\mathrm{TM}}$, rounded to the closest 5-value (rfu)

\begin{tabular}{lllllllllll}
\hline & \multicolumn{1}{l}{$\begin{array}{l}\text { LOD (rfu) Spectrum Compact CE } \\
\text { System }\end{array}$} & \multicolumn{7}{l}{$\begin{array}{l}\text { LOQ (rfu) Spectrum Compact CE } \\
\text { System }\end{array}$} \\
\hline Colour channel & Blue & Green & Yellow & Red & Violet & Blue & Green & Yellow & Red & Violet \\
PowerPlex® ESX17 & 25 & 20 & 20 & 35 & n/a & 60 & 40 & 50 & 75 & n/a \\
PowerPlex® Y23 & 25 & 25 & 20 & 50 & n/a & 50 & 55 & 55 & 105 & n/a \\
Investigator® Argus X-12 QS & 35 & 20 & 20 & 55 & n/a & 75 & 40 & 45 & 120 & n/a \\
NGM Detect & 30 & 30 & 35 & 40 & 30 & 50 & 50 & 75 & 65 & 55 \\
\hline
\end{tabular}


DNA template input), $6986 \mathrm{rfu}$ in the yellow colour channel (at 2 ng DNA template input) and $7137 \mathrm{rfu}$ in the red colour channel (at $750 \mathrm{pg}$ DNA template input). The LOL was reached at $500 \mathrm{pg}$ DNA template input, since no linear signal/template relationship was found after this point, except for in the yellow colour channel, where signal strengths were lower and the linearity extends up to $750 \mathrm{pg}$.

The dynamic ranges of the Spectrum Compact CE System and the ABI Prism ${ }^{\circledR} 310$ Genetic Analyzer of the four colour channels based on the baseline and dilution series analysis of the PowerPlex ${ }^{\circledR}$ ESX17 amplicons are shown in Fig. 2.

\section{1-bp resolution}

\section{ABI Prism ${ }^{\circledast} 310$ Genetic Analyzer}

Allelic ladder peak analysis on the ABI PRISM® 310 Genetic Analyzer showed an average peak-to-valley value of $44.7 \%$ (SD 5.66\%) with the PowerPlex® ESX17 kit at the locus D1S1656 (150-175 bp).
The calculated peak-to valley values for the Gednap 47 trace 4 sample in the locus D1S1656 was $62 \%$ and $46.9 \%$ (Fig. 3b).

\section{Spectrum Compact CE System}

The peak-to-valley values in the shorter fragment length range (150-175 bp) of allelic ladder peaks on average were $17.65 \%$ (SD 2.25\%) (PowerPlex ${ }^{\circledR}$ ESX17) and 59.92\% (SD $4.65 \%$ ) in the longer fragment length range (NGM Detect ${ }^{\mathrm{TM}}$, 290-310 bp).

The calculated peak-to valley values for the Gednap 47 trace 4 sample in the locus D1S1656 were 25\% and $17.9 \%$ for amplicon 1 (Fig. 3a) and 24\% and $18.8 \%$ for amplicon 2 (PowerPlex ${ }^{\circledR}$ ESX17) in the shorter fragment length region and $65 \%$ and $40 \%$ for amplicon 1 and $52.6 \%$ and $42.5 \%$ for amplicon 2 (Fig. 3c) (NGM Detect ${ }^{\mathrm{TM}}$ ) in the longer fragment length region.
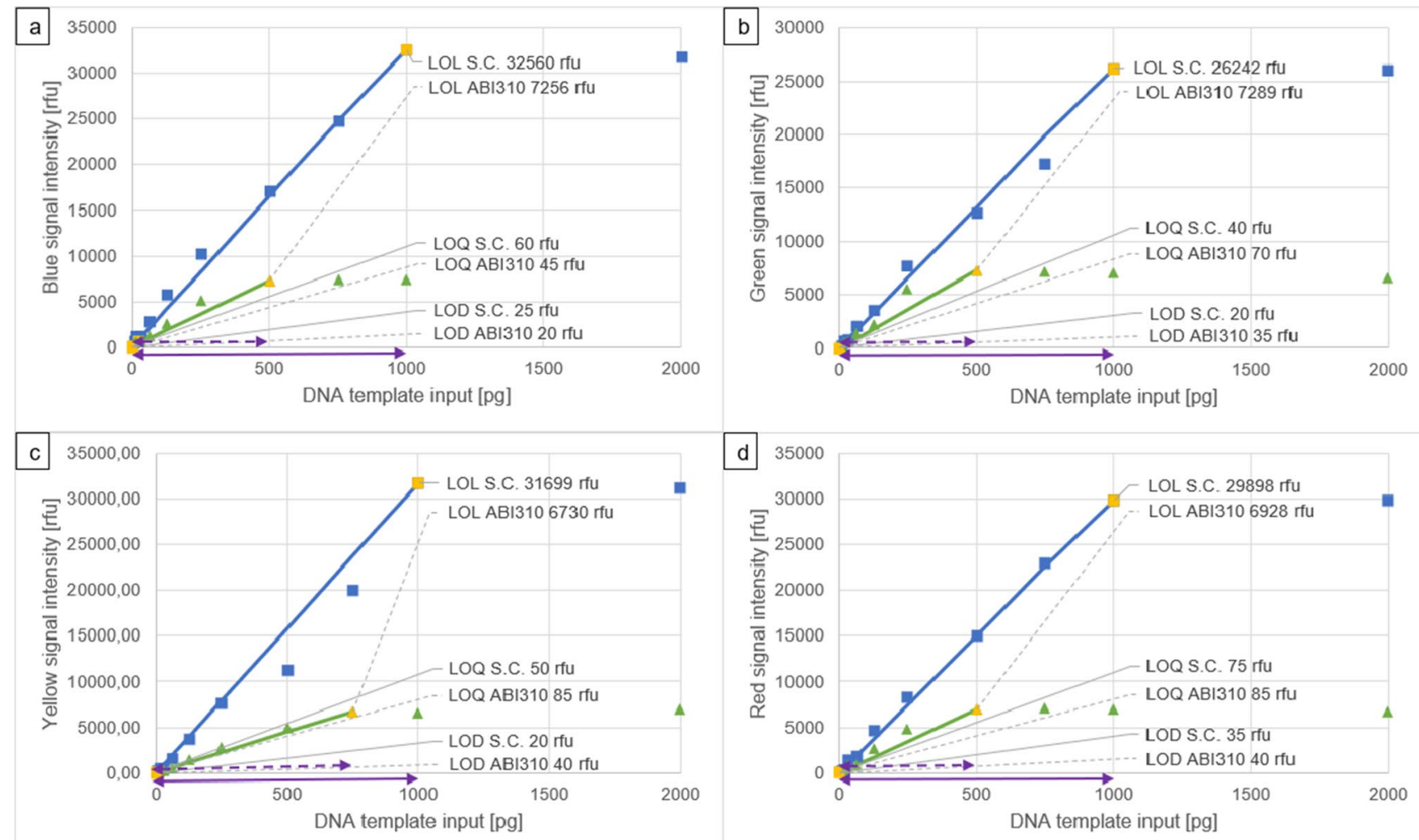

Fig. 2 Dynamic ranges of the Spectrum Compact (S.C.) CE System (continuous arrows) and the ABI Prism ${ }^{\circledR} 310$ (ABI310) Genetic Analyzer (dashed arrows) with the limit of detection (LOD), limit of quantitation (LOQ) and limit of linearity (LOL) thresholds for each instrument for each dye of the PowerPlex ${ }^{\circledR}$ ESX17 kit in relation to

the maximum on-scale peak signals per DNA template input amount, ( $n=76$ for each colour on the Spectrum Compact CE System, $n=19$ for each colour on the ABI Prism ${ }^{\circledR} 310$ Genetic Analyzer); a blue colour channel; b green colour channel; c yellow colour channel; $\mathbf{d}$ red colour channel 


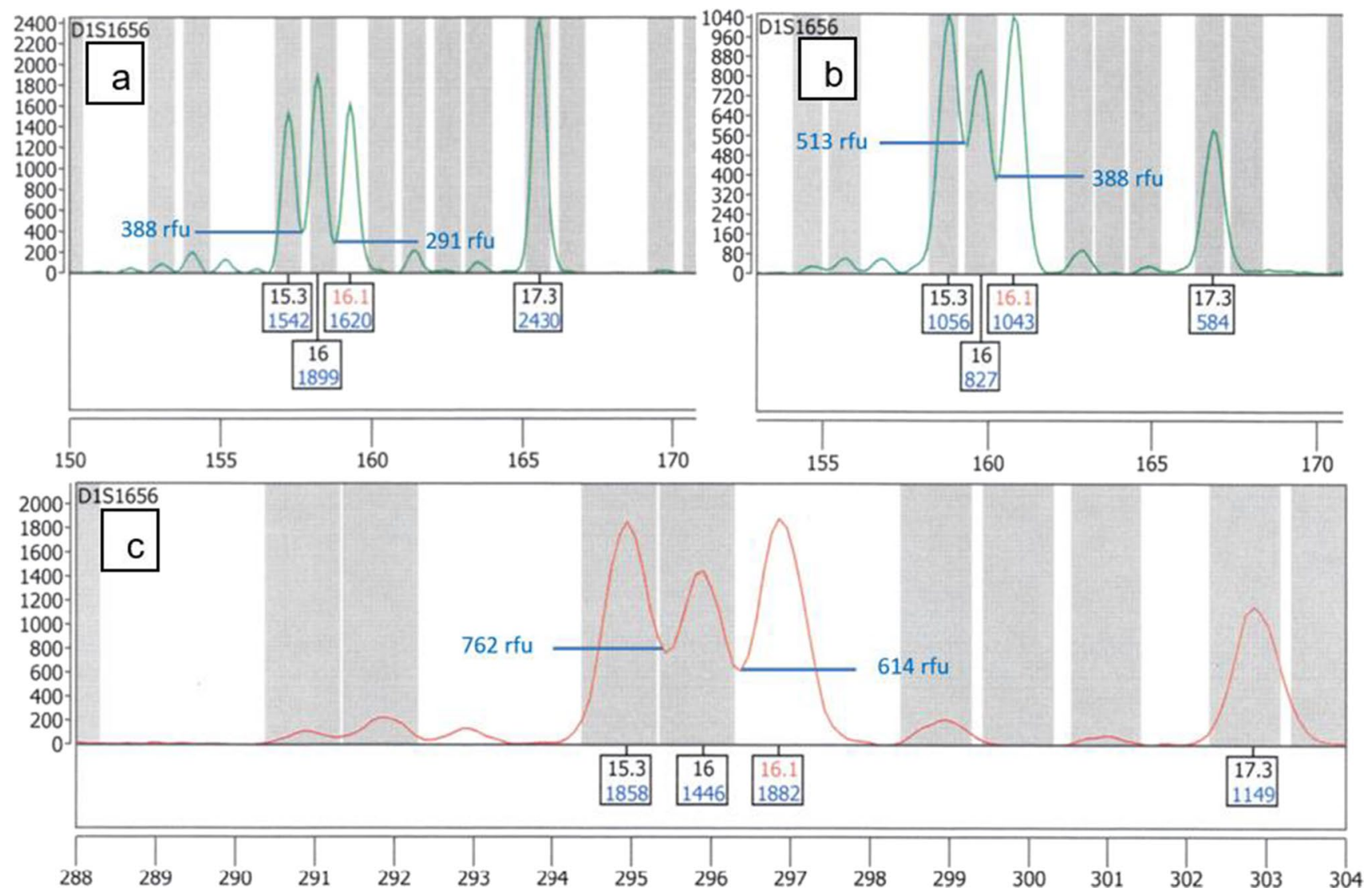

Fig. 3 Electropherograms of Gednap 47 trace 4 sample in the locus D1S1656 with indicated valley heights; a PowerPlex® ESX17 on the Spectrum Compact CE System, amplicon 1; b PowerPlex ${ }^{\circledR}$ ESX17

\section{Mixture resolution}

Complete interpretable mixture profiles were achieved down to a ratio of 1:10 (75 pg +750 pg) with the Spectrum Compact CE System and down to a ratio of 1:5 (100 pg + 500 pg) with the ABI Prism ${ }^{\circledR} 310$ Genetic Analyzer.

In the following, exemplary loci for different major/minor constellations will be shown.

\section{Minor and major heterozygous, no shared alleles}

Mixture loci in which the minor as well as the major were heterozygous and shared no alleles which were analysed on the Spectrum Compact CE System were all readable down to a mixture ratio of 1:30 (except for one dropout incident at 1:30 in D18S51 in one replicate).

The mixture analysis can be seen represented by the locus SE33 in Fig. 4. While the Spectrum Compact CE System analyses show a clear and calculable (1:33.46, Fig. 4e) mixture profile in the lowest mixture ratio, the ABI PRISM ${ }^{\circledR}$ 310 Genetic Analyzer analyses reached their limit of on the ABI PRISM® 310 Genetic Analyzer; c NGM Detect ${ }^{\mathrm{TM}}$ on the Spectrum Compact CE System, amplicon 2

evaluability at the $1: 10$ ratio $(75 \mathrm{pg}+750 \mathrm{pg})$, where the ABI PRISM® 310 Genetic Analyzer exceeds its limit of linearity and produces off-scale peaks and pull-ups (supplemental Fig. 1 in "Online Resource 1").

\section{Minor and major heterozygous, one shared allele}

Mixture loci in which the minor and the major were heterozygous and shared one allele which were analysed on the Spectrum Compact CE System were readable down to a mixture ratio of 1:30.

The mixture analysis analysed on the Spectrum Compact CE System can be seen represented by the locus D16S539 in Fig. 5. While the Spectrum Compact CE System analyses show a clear and readable mixture profile in the lowest mixture ratio (Fig. 5e), the ABI PRISM $® 310$ Genetic Analyzer analyses reached their limit of evaluability at the 1:20 $(50 \mathrm{pg}+1 \mathrm{ng})$ ratio, where the ABI PRISM ${ }^{\circledR} 310$ Genetic Analyzer exceeds its limit of linearity and produces off-scale peaks and pull-ups (supplemental Fig. 2 in "Online Resource $1 ")$. 
Fig. 4 Electropherograms of a mixture of the two DNA amplification positive controls $2800 \mathrm{M}$ and DNA Control 007 in 5 mixture ratios at the locus SE33 (minor alleles 17/25.2 and major alleles 15/16), amplified with the PowerPlex ${ }^{\circledR}$ ESX17 kit and analysed on the Spectrum Compact CE System, only true alleles are labelled; a mixture ratio $1: 1$; b mixture ratio $5: 1$; c mixture ratio $10: 1$; $\mathbf{d}$ mixture ratio $20: 1$; e mixture ratio $30: 1$
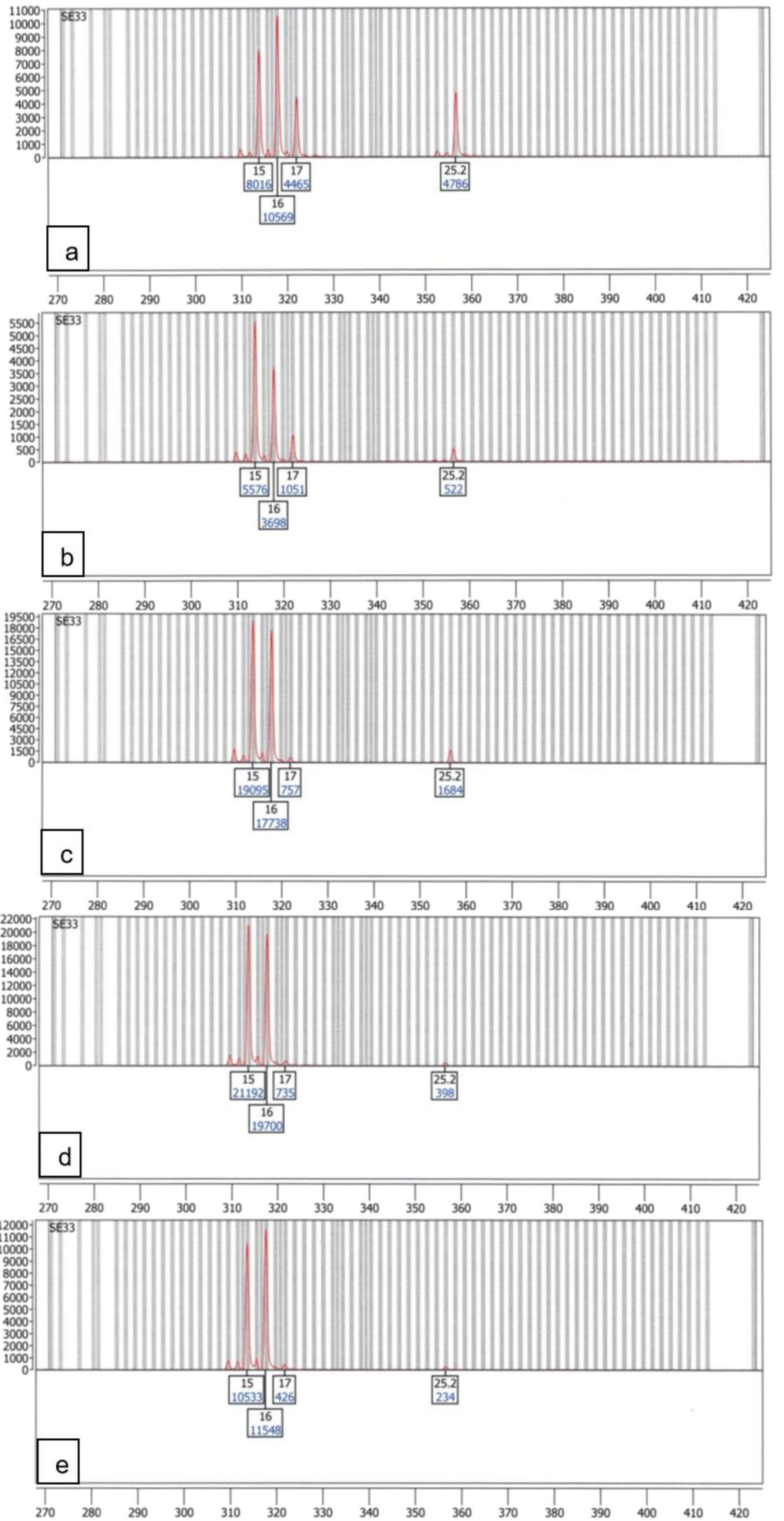

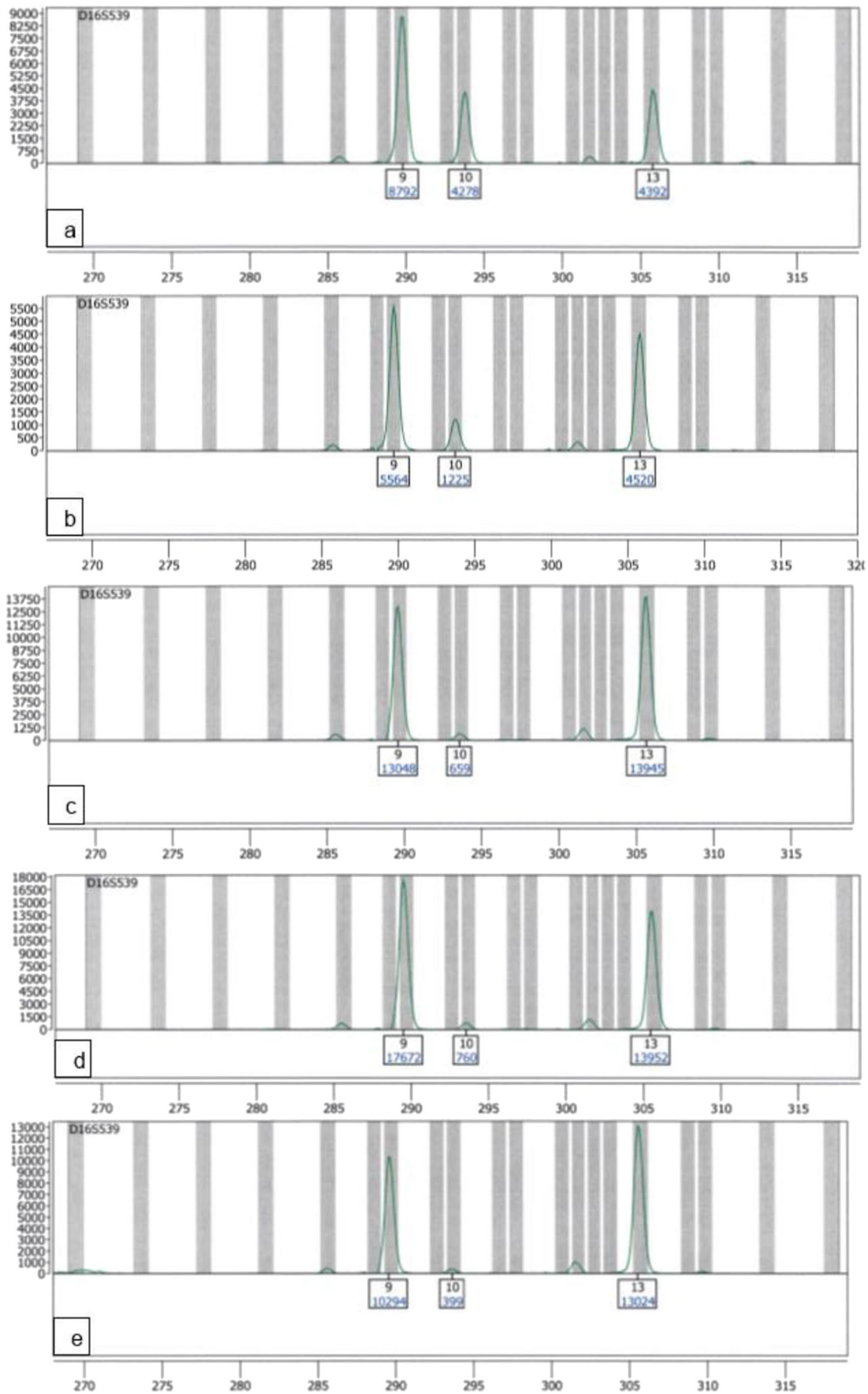
4 Fig. 5 Electropherograms of a mixture of the two DNA amplification positive controls $2800 \mathrm{M}$ and DNA Control 007 in 5 mixture ratios at the locus D16S539 (minor alleles 9/10 and major alleles 9/13) amplified with the PowerPlex ${ }^{\circledR}$ ESX17 kit and analysed on the Spectrum Compact CE System, only true alleles are labelled; a mixture ratio $1: 1$; b mixture ratio 5:1; c mixture ratio 10:1; d mixture ratio 20:1; e mixture ratio $30: 1$

\section{Minor heterozygous, major homozygous, one shared allele}

Mixture loci in which the minor was heterozygous, the major was homozygous and they shared one allele which were analysed on the Spectrum Compact CE System were readable down to a mixture ratio of $1: 10$.

The mixture analysis can be seen represented by the locus D22S1045 in Fig. 6. While the Spectrum Compact CE System analyses show a clear mixture profile (Fig. 6c) in the 1:10 mixture ratio (at which the limit of linearity was reached), the ABI PRISM® 310 Genetic Analyzer analyses reached their evaluability limit at the $1: 10(75 \mathrm{pg}+750 \mathrm{pg})$ ratio, where the ABI PRISM® 310 Genetic Analyzer exceeds its limit of linearity and produces strong pull-ups (supplemental Fig. 3 in "Online Resource 1").

\section{Colour channel balance, heterozygote ratios and stutter}

\section{Colour channel balance}

With the PowerPlex ${ }^{\circledR}$ ESX17 kit, all colour channels performed within $\pm 5 \%$ around their ideal percentage except for the green colour channel (JOE, 6\% deviation) on the Spectrum Compact CE System and the red colour channel (CXR-ET, 7\% deviation) on the ABI PRISM® 310 Genetic Analyzer.

With the PowerPlex ${ }^{\circledR}$ Y 23 kit, all colour channels performed within $\pm 5 \%$ around their ideal percentage except for the blue colour channel (Fluorescein, 6\% deviation) and the red colour channel (CXR-ET, 7\% deviation) on the ABI PRISM® 310 Genetic Analyzer.

With the Investigator ${ }^{\circledR}$ Argus X-12 QS kit, all colour channels performed within $\pm 5 \%$ around their ideal percentage except for the blue colour channel (6-FAM ${ }^{\mathrm{TM}}$, 9\% deviation) on the Spectrum Compact CE System.

With the NGM Detect ${ }^{\mathrm{TM}}$ kit, the colour channels of the Spectrum Compact CE System perform less proportionately. The green colour channel (VIC ${ }^{\mathrm{TM}}$ ) deviates by $8 \%$ and the yellow colour channel (TED ${ }^{\mathrm{TM}}$ ) by $9 \%$ from their ideal percentage.

An overview of the channel balances for the kits PowerPlex $®$ ESX17, PowerPlex $®$ Y23 and Investigator $®$ Argus X-12 QS on the ABI PRISM® 310 Genetic Analyzer and Spectrum Compact CE System, as well as NGM Detect ${ }^{\mathrm{TM}}$ on the Spectrum Compact CE System, is shown in Fig. 7.

\section{Heterozygote ratios}

The heterozygote ratios for an ideal DNA template input of $\sim 250 \mathrm{pg}$ on both instruments with the kits PowerPlex ${ }^{\circledR}$ ESX17 and Investigator® Argus X-12 QS, as well as NGM Detect $^{\mathrm{TM}}$ on the Spectrum Compact CE System were comparable and were mainly above $60 \%$ (supplemental Table 2 in "Online Resource 1"). Outliers of down to $46 \%$ with the PowerPlex ${ }^{\circledR}$ ESX17, 32\% with the NGM Detect ${ }^{\mathrm{TM}}$ and 50\%/30\% (ABI PRISM® 310 Genetic Analyzer/Spectrum Compact CE System) with the Investigator® Argus X-12 QS kit have been observed.

\section{Stutter ratios}

Analyses on the Spectrum Compact CE System showed comparable stutter ratios to the ABI PRISM® 310 Genetic Analyzer (examples for the PowerPlex ${ }^{\circledR}$ ESX17 kit are shown in supplemental Figs. 4 and 5 in "Online Resource 1 ").

\section{Discussion: Advantages and limitations of the Spectrum Compact CE System}

\section{Instruments and consumables}

The Spectrum Compact CE System is a relatively small CE instrument, in actual size as well as in its capacity. With its 4-capillary array and 32-sample tray capacity it is not suitable for laboratories which require a higher sample throughput. When sample numbers that are not divisible by four are run, more consumables are wasted than they would have been with a single capillary instrument. For a small laboratory with a corresponding sample volume, however, a 4-capillary instrument serves as a good compromise when a single-capillary system is no longer available.

The Spectrum Compact CE System can analyse 6 dye channels, which is an improvement compared to the ABI PRISM® 310 Genetic Analyzer and therefore allows the implementation of 6-dye kits like the NGM Detect ${ }^{\mathrm{TM}}$.

The kits used in this study, like most commercially available STR kits, have been developed and validated by the manufacturers with polymer 4 , which is the polymer used for fragment analysis on the Spectrum Compact CE System. This facilitates the use of commercially available kits on the instrument, since one parameter less needs to be adjusted for.

Internal quality checks by the Spectrum Compact $\mathrm{CE}$ System were all passed and conclusive with the observable quality of the results. The calculation of SQ (which is "determined by comparing the fragment pattern observed for the size standard being used against that specified for the size standard in the Sizecalling Protocol" [13]) and the 

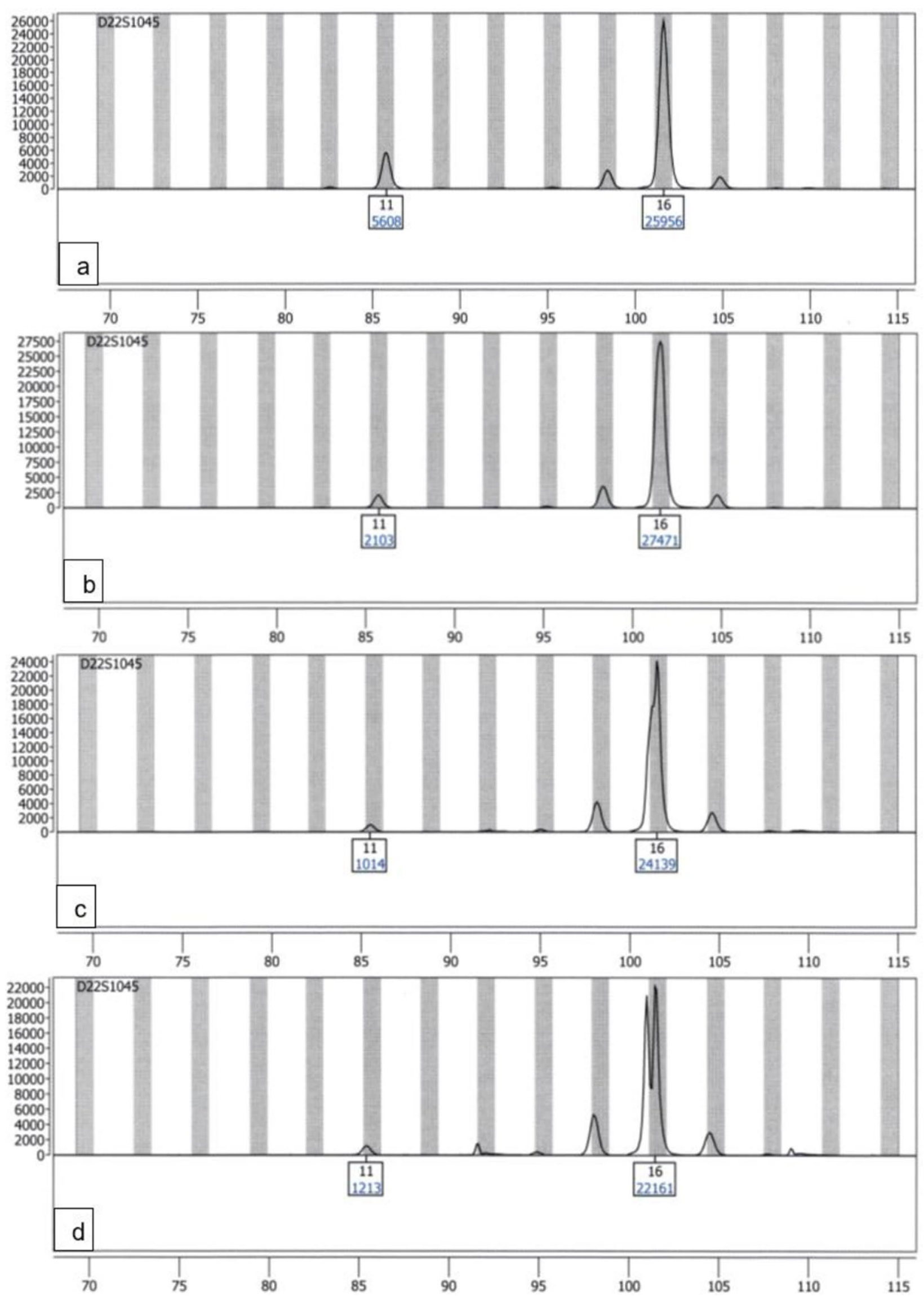
4Fig. 6 Electropherograms of a mixture of the two DNA amplification positive controls $2800 \mathrm{M}$ and DNA Control 007 in 4 mixture ratios at the locus D22S1045 (minor alleles 11/16 and major alleles 16/16), amplified with the PowerPlex® ESX17 kit and analysed on the Spectrum Compact CE System, only true alleles are labelled; a mixture ratio $1: 1$; b mixture ratio $5: 1$; c mixture ratio $10: 1$; $\mathbf{d}$ mixture ratio 20:1, only true alleles are labelled, unlabelled peaks that are not in stutter-positions correspond to pull-ups from other systems

EQ value ("size in bases at which the peak width at half maximal height is equal to the distance between two bases as calculated from the size standard" [13]) was not possible for the MPX5ESSv5 amplicons because there is no specific pre-installed sizing information available on the instrument. A solution for lacking pre-installed data might be found through a software update.

The user interface is intuitive and straightforward and therefore easily learnable. The flexible run set up that can be done on either the touch screen of the instrument or the companion software, which facilitates re-runs and strip-setup corrections. The interface has a panel for consumables that gives a direct overview over the consumables and clearly indicates warnings before and when consumables should be replaced.

The Spectrum Compact CE System has no hard stops, which allows the user to monitor the quality of the analyses at their own discretion if they want to continue using consumables, like the capillary array or the buffers, beyond their recommended injection number. This can save a lot of resources, as demonstrated with the capillary array used in this study which already has been in use for $200 \%$ of its recommended 200 injections. This advantage is comparable to the capillary use of the ABI PRISM $® 310$ Genetic Analyzer, where the capillary could be used beyond its recommended injection number (up to 2000 injections) without loss of analysis quality. Capillary quality can be monitored by observing the peak properties of the analyses which is facilitated by the EQ values given out by the Spectrum Compact CE System.

All consumables are separately integrated in the instrument and can be exchanged or taken out and stored, if the instrument is temporarily not in use. The $2 \mathrm{D}$ barcodes on the consumables are scanned by a hand scanner before they get installed in the instrument, so the information about each individual consumable (charge number, injections left, storage life, etc.) is tracked by the instrument. This means the consumption of polymers, buffers and capillaries is not connected, but depends on the actual usage of each. Stored consumables which are re-installed into the instrument can be recognized by the scanner and the information about whether the consumable should still be used and how many injections it has left is available again. If the 2D barcodes are or become unreadable, they can easily be substituted by scanning separate print-outs of the barcodes of the same lot.
Since the consumables are designed for flexible exchange, their size is intended for fewer injections than the consumables of larger, less flexible instruments. A single polymer cartridge lasts for 64 samples/16 injections and the buffer cartridges for 320 samples/80 injections. The user will therefore, depending on the analysis frequency, have to replace/ reorder them accordingly.

There are no special installation requirements beyond the space needed and a connection to a normal power outlet.

Runs can only be started when there is enough polymer left for the planned run set-up.

The instrument is capable of Sanger-sequencing, but this has yet to be tried by our laboratory.

\section{Spectral calibration and compatibility}

The Spectrum Compact CE System calculates two parameters for the spectral calibration for each capillary in the array. The quality value "describes the confidence with which fluorescent signal from any given dye can be separated from that contributed by the other fluorescent dyes present. The highest theoretical value is 1.0, with no signal from any given fluorescent dye contributing to signal from any of the other fluorescent dyes" [13]. The condition number is a "measure of the degree to which there is overlap in the spectral emission profiles of the dyes used in a given dye set" [13]. Its ideal value would be 1.0.

All spectral calibrations performed were successful as judged by the parameter passes, even though not all matrixes corresponded specifically to a pre-programmed filter assay. The matrix installations for a selection of 8 STR kits from 4 different suppliers that are used in forensic DNA analysis were successful and easily executed because of the pre-programmed spectral calibration programmes. The instrument assays cover a wide range of commonly used commercial STR kits and can be adapted to uncommon or self-made kits using the "Filter" settings, as can be seen with the spectral calibration of the MPX5ESSv5 kit. The instrument compatibility with kits from different manufacturers makes it possible to perform confirmation analyses with kits from different manufacturers on the same instrument.

The spectral calibration of the ABI PRISM® 310 Genetic Analyzer on the other hand is a lot more complex and time consuming, since every colour of the matrix has to be run separately and then combined.

All tested kits produced readable electropherograms with peaks of similar heights which lie between the stochastic threshold and the LOL (except for Investigator ${ }^{\circledR}$ IDPlex Plus in the system TH01), affirming their compatibility with the Spectrum Compact CE System. All colours were differentiated without overlap.

An inter-locus imbalance was noticeable for the kits Investigator ${ }^{\circledR}$ ESSplex SE QS, Investigator ${ }^{\circledR}$ IDPlex Plus 


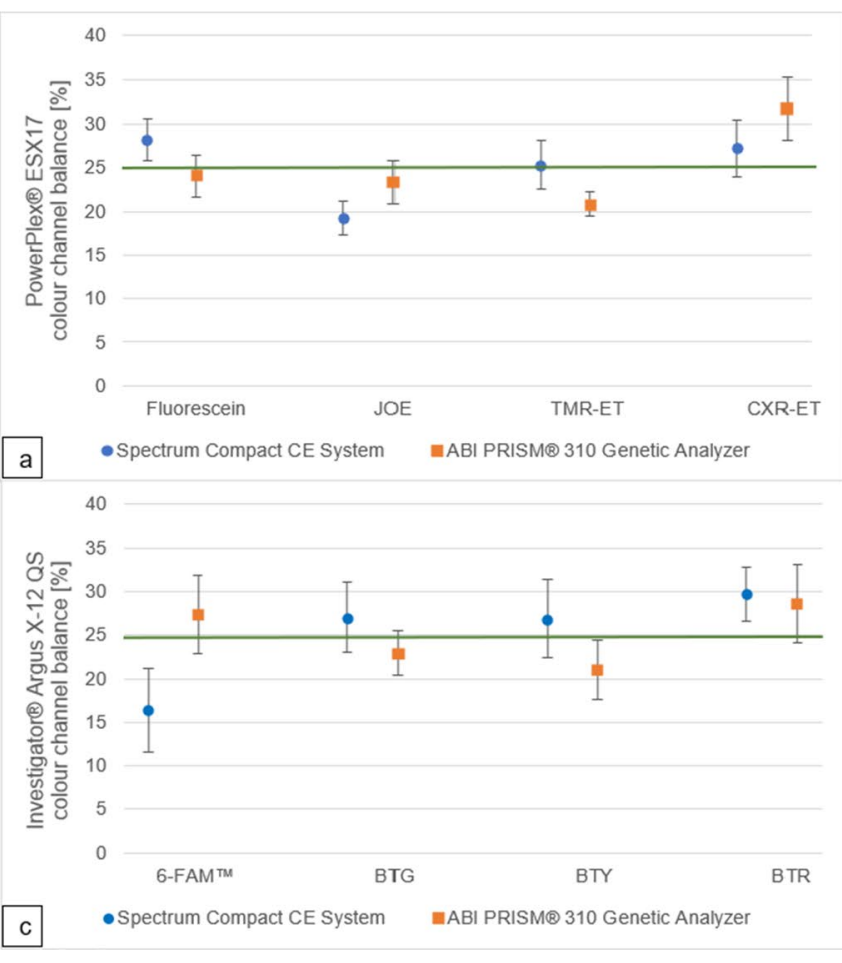

Fig. 7 Colour channel balances (\%) on the Spectrum Compact CE System and the ABI PRISM $® 310$ Genetic Analyzer based on $n=17$ samples per instrument per kit with the ideal percentage share indi-

and Investigator® 24plex QS, which have been applied with a DNA input amount of $\sim 500 \mathrm{pg}$ and a reaction volume of 25 $\mu \mathrm{L}$ as recommended by the manufacturer, since their PCRconditions have not previously been optimized in our laboratory. These imbalances could be improved by optimizing the PCR conditions and are not dependant on the instrument the fragment separation was performed on.

\section{Precision, accuracy and concordance}

The sizing precision value determined in this study concurs with the value of $0.07 \mathrm{bp}$ supplied by Promega [17]. Since the sizing precision was shown to be the same between and within injections, data that was generated using different capillaries and different injections can be confidently compared and analysed with ladders from other injections from the run.

The accuracy of the instrument showed that run conditions inside the Spectrum Compact CE System stay stable enough so that only one allelic ladder is necessary per maximum 31 samples (a run equals max. 8 injections $x 4$ samples including at least one ladder).

A new ladder injection every 10 samples was necessary when working with the ABI PRISM® 310 Genetic Analyzer, but as opposed to the Spectrum Compact CE System, one

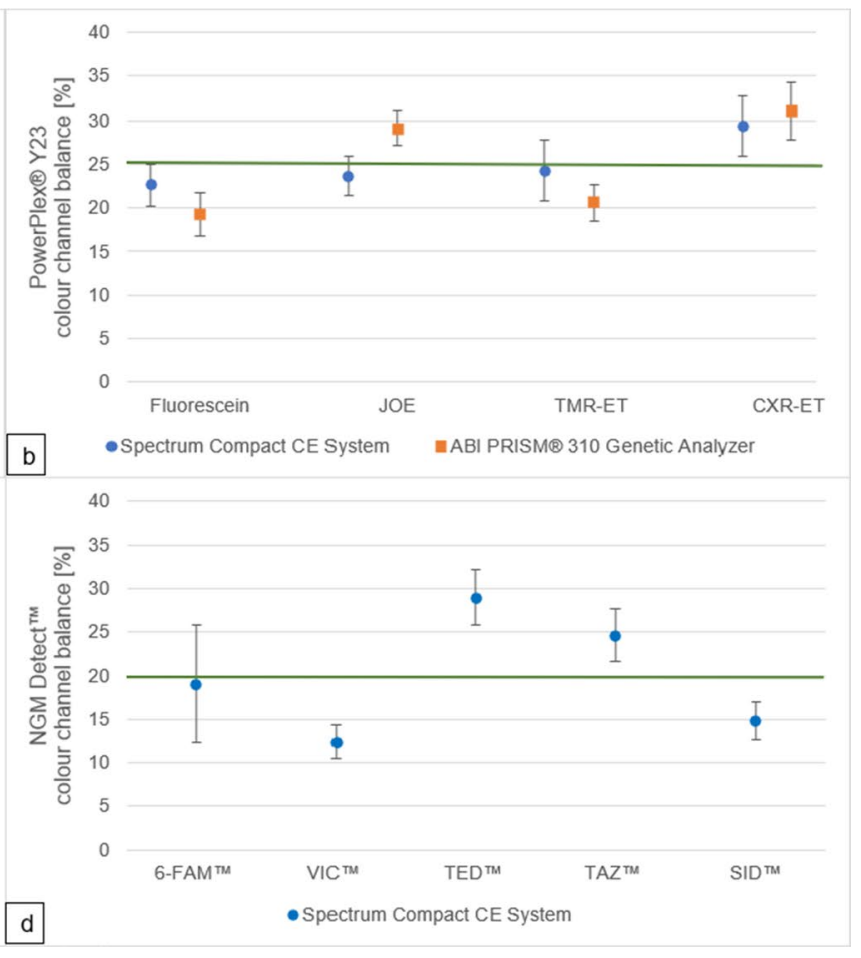

cated by a thick line; a PowerPlex ${ }^{\circledR}$ ESX17; b PowerPlex ${ }^{\circledR}$ Y23; c Investigator® Argus X-12 QS; d NGM Detect ${ }^{\mathrm{TM}}$

allelic ladder tube can be reinjected by itself several times for an analysis of up to 47 samples in one run.

All samples analysed which had known results were concordant with known control DNA alleles and/or the results of the ABI PRISM® 310 Genetic Analyzer.

\section{Baselines and carry-over}

The limits of detection which were determined based on the baseline of the Spectrum Compact CE System were comparable to those of the ABI PRISM $₫ 310$ Genetic Analyzer. The LODs set based on the baseline analysis were applied separately for each colour channel in this study. If a single threshold had been set as the highest LOD ( $35 \mathrm{rfu}$ ), 4 allele calls (1.7\% of all expected alleles) would have been missed in the PowerPlex ${ }^{\circledR}$ ESX17 dilution series on the Spectrum Compact CE System.

On the ABI PRISM® 310 Genetic Analyzer, 3.3\% of allele calls would have been lost with a universal threshold of $40 \mathrm{rfu}$, supporting the colour channel specific threshold approach.

No carry-over has been observed in any negative controls. 


\section{Dynamic range with thresholds}

The dynamic range of the Spectrum Compact CE System goes up to twice the DNA template input amount of what the ABI PRISM® 310 Genetic Analyzer is able to analyse (1 $\mathrm{ng}$ as opposed to $500 \mathrm{pg}$ ). For the Spectrum Compact CE System, the theoretical cut-off of 32,767 rfu was almost reached (99.37\%) by the highest observed on-scale peak of $32,560 \mathrm{rfu}$ in the blue channel at $1 \mathrm{ng}$ DNA template input with the PowerPlex® ESX17 kit.

On the ABI PRISM ${ }^{\circledR} 310$ Genetic Analyzer, the highest observed on-scale peak of $7444 \mathrm{rfu}$ in the blue channel at 750 pg DNA template input with the PowerPlex ${ }^{\circledR}$ ESX17 kit came close to the theoretical cut-off of $8192 \mathrm{rfu}(90.87 \%)$.

The higher dynamic range of the Spectrum Compact CE System allows for the analysis of highly degraded DNA samples.

At low DNA template input amounts, the sensitivity of the two instruments is comparable, making the analysis of low template DNA samples on the Spectrum Compact CE System possible.

The stochastic thresholds were set using the mean of all heterozygous peaks at DNA template input levels where drop-outs occur $(\sim 16 \mathrm{pg}$ and $\sim 8 \mathrm{pg})$ plus $3 \mathrm{SD}$ which includes all tallest false homozygotes found in this study. The stochastic threshold determined for the Spectrum Compact CE System was higher than the one determined for the ABI PRISM® 310 Genetic Analyzer, which is consistent with the findings that the Spectrum Compact CE System produces higher signal peaks at the same DNA template input amounts.

\section{1-bp resolution}

The Spectrum Compact CE System showed better 1-bp resolution than the ABI PRISM ${ }^{\circledR} 310$ Genetic Analyzer and was able to provide clear peak resolution even in the longer fragment range.

\section{Mixture resolution}

Due to the higher dynamic range of the Spectrum Compact CE System, mixtures of higher contributor DNA amount differences can be analysed than on the ABI PRISM ${ }^{\circledR} 310$ Genetic Analyzer since higher amounts of DNA template input are possible without overloading the detection unit.

The overall interpretation of mixture profiles could be aided by secondary analysis with kits that have a different locus distribution, as to differentiate real peaks from pull-ups.

\section{Colour channel balance, heterozygote ratios and stutter}

The colour channel balance between the two instruments is comparable, with the red colour channel being stronger than the other channels if CXR-ET is analysed on the ABI PRISM ${ }^{\circledR} 310$ Genetic Analyzer and 6-Fam ${ }^{\mathrm{TM}}$ being weaker in the Investigator ${ }^{\circledR}$ Argus X-12 QS kit on the Spectrum Compact CE System.

The NGM Detect ${ }^{\mathrm{TM}}$ seems to be less balanced than the other kits, but that could stem from the spectral calibration assay being configured for a NED ${ }^{\mathrm{TM}}$ yellow dye and not a $\mathrm{TED}^{\mathrm{TM}}$ as is used in the kit.

Heterozygote ratios and stutter ratios are comparable on both instruments and no influence beyond PCR-factors was noticed.

\section{Sample analysis}

The sample throughput of 4 samples/42 min is higher than on the ABI PRISM® 310 Genetic Analyzer (roughly 1 sample/35 min).

To analyse samples on the Spectrum Compact CE System that have been amplified by a kit for which the instrument has pre-installed run assays, no parameter adjustments are necessary.

On the ABI PRISM® 310 Genetic Analyzer, each run parameter has to be selected manually if more than one kit requiring different run parameters is part of one run, while the run parameters on the Spectrum Compact CE System are integrated in the specific run modules of each kit. This facilitates the run-setup as it is less time consuming and less prone to human error.

The.fsa files generated were compatible for analysis with the GenoProof Mixture 2 software.

\section{Conclusion}

The Spectrum Compact CE System meets the requirements for forensic DNA analysis and of a laboratory with a high diversity of samples (e.g. low template DNA, degraded DNA, mixtures with a strong major/weak minor) and times of usage.

We assess that the Spectrum Compact CE System is a suitable tool for DNA-fragment separation and will continue to gather data about our experience working with it.

\section{Availability of data}

Not applicable. 
Supplementary Information The online version contains supplementary material available at https://doi.org/10.1007/s00414-021-02673-1.

Acknowledgements We would like to thank Theresa Seider from the Institute of Forensic Medicine of the University Erlangen-Nürnberg, Erlangen, Germany, for gifting us a leftover Matrix Standard set for the MPX5ESS kit by Serac.

We were gifted an Investigator ${ }^{\circledR}$ ESSplex SE QS kit (100), an Investigator ${ }^{\circledR}$ IDplex Plus kit (100), an Investigator ${ }^{\circledR} 24$ plex QS kit (100), a Matrix Standard BT5 multi cap. $(25 \mu \mathrm{L})$ and a Matrix Standard BT6 $(50 \mu \mathrm{L})$ by Qiagen $\mathrm{GmbH}$, Hilden, Germany. We were also gifted a DS-31 Matrix Standard kit (dye set J6-T) (previously opened and used by Thermo Fisher Scientific Life Technologies GmbH, Darmstadt, Germany) by Thermo Fisher Scientific GmbH. All items were received with the explicit purpose to be tried on the Spectrum Compact CE System.

Funding Open Access funding enabled and organized by Projekt DEAL.

Code availability Not applicable.

\section{Declarations}

Ethics approval Not applicable.

Consent to participate All individuals whose DNA samples have been used in this study have given their written consent to use their buccal swab DNA extracts for scientific purposes according to $\S 13$ of the German law of genetic diagnostics.

Consent for publication Not applicable.

Conflict of interest The authors declare no competing interests.

Open Access This article is licensed under a Creative Commons Attribution 4.0 International License, which permits use, sharing, adaptation, distribution and reproduction in any medium or format, as long as you give appropriate credit to the original author(s) and the source, provide a link to the Creative Commons licence, and indicate if changes were made. The images or other third party material in this article are included in the article's Creative Commons licence, unless indicated otherwise in a credit line to the material. If material is not included in the article's Creative Commons licence and your intended use is not permitted by statutory regulation or exceeds the permitted use, you will need to obtain permission directly from the copyright holder. To view a copy of this licence, visit http://creativecommons.org/licenses/by/4.0/.

\section{References}

1. Brettell TA, Butler JM, Saferstein R (2005) Forensic science. Anal Chem 77(12):3839-3860. https://doi.org/10.1021/ac9008786

2. Frumkin D, Wasserstrom A, Budowle B, Davidson A (2011) DNA methylation-based forensic tissue identification. Forensic Sci Int Genet 5(5):517-524. https://doi.org/10.1016/j.fsigen.2010.12.001
3. Haas C, Klesser B, Maake C, Bar W, Kratzer A (2009) mRNA profiling for body fluid identification by reverse transcription endpoint PCR and realtime PCR. Forensic Sci Int Genet 3(2):80-88. https://doi.org/10.1016/j.fsigen.2008.11.003

4. Jeffreys AJ, Wilson V, Thein SL (1985) Individual-specific fingerprints of human DNA. Nature 316(6023):76-79. https://doi.org/ $10.1038 / 316076 \mathrm{a} 0$

5. Warner M (1994) Migrating toward capillary electrophoresis. Anal Chem 66(22):1137A-1141A. https://doi.org/10.1021/ac000 $94 \mathrm{a} 002$

6. Williams PE, Marino MA, Del Rio SA, Turni LA, Devaney JM (1994) Analysis of DNA restriction fragments and polymerase chain reaction products by capillary electrophoresis. J Chromatogr A 680(2):525-540. https://doi.org/10.1016/0021-9673(94) $85152-2$

7. Butler JM, Mccord BR, Jung JM, Lee JA, Budowle B, Allen RO (1995) Application of dual internal standards for precise sizing of polymerase chain-reaction products using capillary electrophoresis. Electrophoresis 16(1):974-980. https://doi.org/10.1002/elps. 11501601163

8. Isenberg AR, McCord BR, Koons BW, Budowle B, Allen RO (1996) DNA typing of a polymerase chain reaction amplified D1S80/amelogenin multiplex using capillary electrophoresis and a mixed entangled polymer matrix. Electrophoresis 17(9):15051511. https://doi.org/10.1002/elps.1150170916

9. Marino MA, Weaver KR, Tully LA, Girard JE, Belgrader P (1996) Characterization of mitochondrial DNA using low-stringency single specific primer amplification analyzed by laser induced fluorescence-capillary electrophoresis. Electrophoresis 17(9):14991504. https://doi.org/10.1002/elps.1150170915

10. Kuffner CA, Marchi E, Morgado JM, Rubio CR (1996) Capillary electrophoresis and Daubert: time for admission. Anal Chemi 68(7):241A-246A. https://doi.org/10.1021/ac9618839

11. Wenz H, Robertson JM, Menchen S, Oaks F, Demorest DM, Scheibler D, Rosenblum BB, Wike C, Gilbert DA, Efcavitch JW (1998) High-precision genotyping by denaturing capillary electrophoresis. Genome Res 8(1):69-80. https://doi.org/10.1101/gr.8.1. 69

12. PubMed. <https://pubmed.ncbi.nlm.nih.gov/>, (accessed 18.01.2021.).

13. Spectrum Compact CE System Operating Manual Instructions for use of CE1304, 2020.

14. Personal communication with Promega Corp.

15. J.M. Butler, Stochastic thresholds and allele drop-out, Advanced topics in forensic DNA typing: interpretation, Elsevier Inc. 2015, $3^{\text {rd }}$ edition, p. 95.

16. Walsh PS, Metzger DA, Higuchi R (1991) Chelex-100 as a medium for simple extraction of DNA for Pcr-based typing from forensic material. Biotechniques 10(4):506-513. https://doi.org/ 10.2144/000114018

17. R.W. Burkhard Loffeld, Promega Userseminar im Rahmen des 41. Spurenworkshops 2021.

Publisher's Note Springer Nature remains neutral with regard to jurisdictional claims in published maps and institutional affiliations. 